\title{
Aby Warburg: el terror y la cura
}

\section{(1) Floncia Abadi}

Universidad de Buenos Aires - Consejo Nacional de Investigaciones Científicas y Técnicas, Argentina

I

Es probable que el terror a las serpientes se deba menos al veneno que algunas poseen que al carácter sinuoso y deslizante de sus movimientos. Balaji Mundkur afirma que existen "reacciones biológicas que la mera percepción de los movimientos serpenteantes del reptil provoca en el sistema nervioso" (Warburg, 2004: 92). No debe extrañar entonces que la última Pathosformel de Aby Warburg, la última imagen fóbico-pasional a la que dedica un escrito, sea la serpiente, que condensa movimiento y pavor. La serpiente -cuyo culto trasciende ampliamente la tradición greco-romana a la que Warburg consagra la mayor parte de su obra- se erige como el símbolo culminante del terror esquizofrénico warburguiano, presente ya en el ondear de los cabellos "serpentinos" de la ninfa.

La imagen de la serpiente ilumina un tópico central de la obra y la vida de Warburg: el tópico de la cura, que designa una larga tradición que atraviesa toda la historia del pensamiento (el Denkraum), desde el mago hasta el médico. Como se sabe, la serpiente acompañaba a Asclepio, el dios griego de la medicina, y es símbolo tanto de muerte y aniquilamiento como de transformación, regeneración e inmortalidad. La cura que la serpiente simboliza es impensable sin el terror que produce. Si no fuéramos aterrorizables, intimidables, sugestionables, frágiles, capaces de transferir a otro nuestro propio poder hasta vaciarnos, no seríamos tampoco curables. En el contexto de la obra de Warburg, la cura nombra un camino, un tránsito - por definición transitorio, es decir, precario- de la locura aterrorizada y sufriente (la manía) a la calma contemplativa y reflexiva (la sophrosyne). Ese camino no puede nunca borrar su origen terrorífico: si este miedo desapareciera, desaparecería la cura misma. (Por eso, una interpretación evolucionista del pensamiento de Warburg, aún teniendo prueba textual, no le saca el mayor provecho).

La entera tradición de la cura pone en juego el vínculo con un otro investido de autoridad, cuyo prestigio produce un efecto intimidatorio. Pero la investidura es siempre un ropaje insustancial, una proyección (como el poder del cofre que se revela vacío en The Devils, de Ken Russell, y que aún así sugestiona a una multitud hasta la posesión). De ahí que lo más relevante de la distinción entre simulacros que curan y simulacros que envenenan (que suele trazarse teniendo en cuenta los diálogos platónicos Fedroy 
República) sea menos el vínculo entre veneno y remedio (el célebre phármakon) que el carácter de simulacro de aquello que cura y envenena. La cura es un efecto benéfico de ese simulacro; la mala utilización de este, en cambio, define al abuso. Si no hubiera de por medio una transferencia de poder, el efecto no se produciría. El buen médico entiende que su función es entonces la del mago, es decir que no es la medicina o el medicamento aquello que cura sino la persona del médico, en la medida en que ejerce una autoridad que ordena tomarlo (hace la orden). Las órdenes apelan al inconsciente (al alma irracional): se dirigen a las fibras permeables y miméticas que son capaces de obedecer con la menor resistencia, capaces de hipnosis, de sugestión, de creencia. Sin la "entrega abismática" a la que se refiere Warburg no puede haber sanación alguna.

\section{II}

La creencia es indispensable para la curación en dos sentidos. En primer lugar, da lugar a la autoridad de aquel que, en la medida en que se crea en él, tendrá el poder de curar. Tal acto de creer se asienta en la capacidad del sujeto para confiar en otros, y supone por tanto cierta inocencia, cierta credulidad. La capacidad humana de otorgar un poder que brinda a un otro un prestigio intimidante es la base del carácter erótico de la transferencia sanadora. El deseo se alimenta de esa intimidación, de ese prestigio. En segundo lugar, la creencia es indispensable en la creación del lazo afectivo, que hace al carácter amoroso de la transferencia. Deseo y amor son dos aspectos de la relación transferencial que es preciso distinguir. Si el deseo requiere el terror, el amor es aquello que lo transmuta y da a la cura su cumplimiento. Como ha afirmado Stephen Levine, curar es tocar con amor lo que antes fue tocado con miedo.

La creencia, entonces, permite el lazo amoroso. Esto puede verse con claridad en el film $E l$ regreso de la mujer pantera, de Robert Wise y Gunther von Fritsch, secuela de la célebre película de Jacques Tourner, La mujer pantera. Amy es una niña introspectiva y soñadora que carece de amistades ya que su entorno la rechaza. A raíz de un anillo que recibe de una vecina anciana, establece contacto con el espíritu de Irena, la primera mujer fallecida del padre (la mujer pantera, protagonista del film de Tourner), con quien conversa y juega en el jardín largos ratos, y que se convierte en su único lazo amistoso. El padre, Oliver, se irrita enormemente con la niña cada vez que esta afirma que, allí en el jardín, está su amiga (que él, naturalmente, no ve). Luego de una escena en que la reprende y encierra a modo de castigo, Amy decide escapar. El padre recibe entonces los consejos de la profesora de Amy, que le señala que el castigo aísla aún más a su hija, y que el modo de establecer un lazo con ella es creerle. Luego de una épica búsqueda entre la nieve, Oliver encuentra a Amy, y la última escena, con la niña ya de retorno en la casa, nos muestra al padre que mira hacia el jardín y pregunta a su hija: “'hay alguien allí?”; ella ve el fantasma de Irena y responde: "sí, allí está", a lo que el padre afirma "te creo, ahí está".

Sin creencia, no hay solución al conflicto del aislamiento, es decir, no hay lazo afectivo. La creencia es la clave de la re-conciliación, del re-ligare. La increencia, en contraste, es el camino de la separación. Si en La mujerpantera Oliver no le cree a Irena, en esta secuela no le cree a Amy. En ambos casos, la creencia en el otro está asociada a una creencia en lo sobrenatural, lo mágico, lo que excede la percepción. Sabemos que para ver, primero hay que creer, es decir, creer en lo que no se ve. Ni Irena ni Amy mienten jamás a lo largo de las películas, y dudar de sus palabras solo porta peligros.

Sin embargo, en el proceso de curación, ese otro al que se cree, al que se le transfiere un poder y con quien se establece un lazo afectivo, es en realidad un mediador. El proceso global es un proceso de autocuración, como supo expresar insistentemente Aby Warburg. Desde su perspectiva, esta autocuración estaba íntimamente ligada 
con su labor profesional: "para mí, el ocuparme de mi investigación profesional es un claro síntoma de que mi naturaleza aun quiere salir por sí sola de este pantano" (Binswanger, Warburg, 2007: 195-196); o cuando se a refiere a su búsqueda de "autoliberación" (selbstbefreiung) "a través del recuerdo de mis intentos por iluminar la psicología del Renacimiento" (Binswanger, Warburg, 2007: 189). Aparentemente, esta concepción estuvo a la base de la elección de Ludwig Binswanger como su médico, quien se refería a una "autocuración existencial expresiva", que consistía en superar las fobias mediante el trabajo habitual del paciente. La conferencia sobre El ritual de la serpiente quedaría apuntada como un hito de ese modo de sanación, de ese "Renaissance” personal, como lo llamó Warburg, identificándose con su objeto de estudio.

\section{III}

"Symbol tut wohl" (el símbolo hace bien), cuenta Max Warburg que decía su padre. Sin duda, Binswanger se topó con un paciente cuya profesión era especialmente apta para su método. Si el mago, el médico y sus variantes pueden ser vistos como mediadores de un proceso de autocuración, las imágenes simbólicas con las que trabajaba Warburg tienen un peso propio en tal proceso. La razón es simple: estas median entre el terror y el pensamiento, es decir, operan directamente sobre lo que Warburg llamó la experiencia hipomágica del miedo, que clama por la representación para atenuarse, para aliviarse. "Entre el hombre salvaje y el hombre que piensa, está el hombre de las interconexiones simbólicas" (Warburg, 2004: 27).

El terror es, desde esta perspectiva, el fundamento último del pensamiento, su más íntima alteridad, y pensar, una forma de exorcizar ese terror que conlleva la sanación. En este sentido, Warburg se refiere en la Introducción al proyecto Mnemosyne a un proceso de desdemonización del acervo común de impresiones fóbicamente marcadas. Se trata de lidiar con los demonios, con un pavor que proviene de lo más profundo y originario de la experiencia, y que luego se proyecta afuera, en una visión del entorno y la naturaleza como hostiles, como enemigos que deben ser controlados y aplacados. Eso mismo sufría Warburg diariamente en la clínica de Binswanger; en la descripción del doctor Embden: "El entorno, el médico, las enfermeras, eran interpretadas como hostiles sin excepción" (Binswanger, Warburg, 2007: 61). El único medicamento que Warburg tuvo para este mal, llamado en su momento "delirio de perjuicio presenil", fue el símbolo. Y no fue en esto una excepción: la concepción de Warburg se replica en las célebres declaraciones de Picasso sobre la pintura luego de visitar el Museo del Trocadero en 1907 (primer museo etnográfico de París) y entrar en contacto por primera vez con los fetiches y máscaras del arte africano: la pintura, afirma, consiste en una mediación con las fuerzas hostiles del entorno; las máscaras son objetos mágicos, "intercesseurs" que se oponen a "los espíritus desconocidos y amenazantes". Símbolo, magia, mímesis, máscaras: nombres del umbral que da lugar (espacio, Raum) a la cura. No casualmente Warburg expresó su intención de estudiar medicina cuando terminó su trabajo sobre Botticelli.

Si la muerte que sugiere el símbolo de la serpiente es necesaria en el proceso de curación se debe al vínculo indisociable entre el miedo, el movimiento y la vida. La vida que piensa Warburg es por necesidad fóbica, estremecimiento, movimiento en todas sus etapas. El Renacimiento reanima los "engramas fóbicos" del paganismo: se trata del movimiento como "gesto vivo" de la Antigüedad, que descubre Warburg contra la quieta grandeza de Winckelmann. En vida, la herida no puede sanarse por completo: el proceso de autocuración es infinito, la calma contemplativa no se alcanza nunca en su totalidad. Warburg lo sabía y por eso se describió como un "esquizoide incurable". También lo supo Quirón, gran médico de la mitología griega, que renuncia a la inmortalidad al recibir una herida incurable incluso para él (cuando Hércules 
lo hiere accidentalmente con una flecha envenenada, le produce una herida imposible de ser sanada y entonces intercambia con Prometeo la liberación de este por la mortalidad). El sufrimiento es imposible de ser eliminado sin la ayuda de la muerte; vida y terror son inseparables. En el Fedro, Sócrates afirma que la manía nace del dios, mientras que la sophrosyne nace entre los hombres. Como camino que atraviesa la vida hacia la muerte, la cura es la dimensión humana por excelencia.

\section{IV}

Hacia dónde debe llevar el camino del símbolo, hasta dónde este debe ser superado hacia un modo científico de pensar, es tema de larga discusión en la literatura sobre Warburg. Desde nuestra perspectiva, se trata de comprender si la calma contemplativa, la sophrosyne, puede equipararse a la razón científica.

En principio, parece claro que Warburg asocia su propia locura con la imposibilidad de establecer nexos causales, así como su cura con la posibilidad de restablecer tales nexos. Cuando relata la historia de su enfermedad coloca el origen de esta a su edad de seis años, cuando contrae tifus, y afirma:

De ese tiempo procede el miedo que provocaron los desproporcionadamente inconexos recuerdos visuales o excitaciones sensoriales de los órganos olfativos o auditivos, la angustia que provocaba el caos, el intento de poner orden intelectualmente en este caos...un intento que puede ser calificado como la trágica tentativa infantil del hombre pensante, realizada en consecuencia muy tempranamente, demasiado tempranamente para mi constitución nerviosa (Binswanger, Warburg, 2007: 176).

El "campo ilógico de los colores, olores y sonidos" lo habría enfermado, dañando nada menos que su "confianza en la vida" (Binswanger, Warburg, 2007: 177). Cuando en 1924 siente recuperar su salud, en cambio, escribe: "reconozco con agradecimiento que de nuevo comienzo a pensar de modo científico"; "hablé espontáneamente una hora y media, no perdí el hilo y realicé un estrecho encadenamiento de observaciones contextuales sobre psicología de la cultura con todo mi anterior trabajo" (Binswanger, Warburg, 2007: 191-192).

Mucho se ha dicho, sin embargo, sobre la postulación en la obra de Warburg de una causalidad no científica, que está presente en las danzas del pueblo de Oraibi y en los rituales de los indios Hopi y que tiene en el símbolo su núcleo operativo. El título original de la conferencia de Kreuzlingen rezaba "Sobre la lógica en la magia del hombre primitivo" [Über die Logik in der Magie des primitiven Menschen]. La "causalidad danzada" (getanzte Kausalität) era la conexión entre la fuerza de la naturaleza y el hombre, en que el conector era precisamente el símbolo. La relación entre la serpiente y la lluvia es vista también como causada mágicamente, mediante la semejanza mimética entre la forma de la serpiente y la del rayo. Phillip Ekardt ha hecho un excelente trabajo explicando en este sentido la función de la mímesis. Roberto Calasso, por su parte, ha insistido sobre la metamorfosis y la posesión como formas del conocimiento.

A estos comentarios quisiera agregar una cuestión más. Aquella confianza en la vida, cuyo daño cifra la enfermedad, no fue nunca para Warburg meramente una cuestión de lógica, ni científica ni tampoco mágica, y recuperarla requirió, sobre todo, de lo que entendió como visión del mundo sub gratia, y no solo sub natura o sub lege. La razón científica es para Warburg la fusión entre la ley y la naturaleza; así se refiere a "el tiempo de creencia en la ley inherente a la naturaleza, de la concepción científiconatural del mundo" (Binswanger, Warburg, 2007: 180). Según afirma, la mirada de 
la gracia le fue transmitida por su niñera protestante, suavizando el estricto judaísmo de las leyes de su familia paterna, y luego también su mujer y su cuñado y amigo. La calma contemplativa requiere no solo de nexos causales que ordenen el caos, sino de la confianza, es decir, de creencia en un entorno (o un dios) benevolente. Para Warburg, la cosmovisión animista de los indios estaba más cerca de esa benevolencia que la ciencia. No hay en ello ningún romanticismo, sino la mirada aguda de un cuerpo atravesado por el terror que busca establecer lazos, hilos, que lo unan al mundo del que se ha separado. 


\section{Q Bibliografía}

" Binswanger, L. y Warburg, A. (2007). La curación infinita. Historia clínica de Aby Warburg (Trad. Gelormini, N.). Buenos Aires: Adriana Hidalgo.

"Calasso, R. (2008). La locura que viene de las ninfas (Trad. Ramírez Vladillo, T.). México: Sexto piso.

»Ekardt, P. (2011). Sensing, feeling, imitating. Psycho-Mimeses in Aby Warburg. ilinx (2).102-121.

»Warburg, A. (2004). El ritual de la serpiente (Trad. Homaeche, J.). México:Sexto piso.

»Warburg, A. (2010). Atlas Mnemosyne (Trad. Chamorro Mielke, J.). Madrid: Akal. 